\title{
Evaluation of flexural strength of hipped and presintered zirconia using different estimation methods of Weibull statistics
}

\author{
Stawarczyk, Bogna ; Özcan, Mutlu ; Trottmann, Albert ; Hämmerle, Christohp H F ; Roos, Malgorzata
}

\begin{abstract}
OBJECTIVES: This study determined the flexural strength of one hipped and eight presintered zirconia and evaluated the results using different estimation methods of Weibull statistics. MATERIALS AND METHODS: Presintered zirconia specimens were prepared in white state and sintered according to each manufacturer's instructions. One hipped zirconia acted as the control group. The specimens were loaded in a Universal Testing Machine (ISO 6872, 2008). Data were analysed using "normal" (Levene test, one-way ANOVA, Scheffé test) and "Weibull distribution" estimated by either Least Squares (LS) (mean (Excel) and median rank (MINITAB)), Maximum Likelihood (ML) (MINITAB) or ML (MINITAB) with a correction of BS EN 843-5 (2006) (MLC) (alpha=0.05). RESULTS: According to normal $(\sigma)$ and Weibull distribution (s), three-point flexural strength (MPa) of the hipped zirconia ( $\sigma=1643$ (1507; 1782), s(LS mean rank): 1772, s(LS median rank): 1751 (1619; 1894), s(ML): 1733 (1645; $1826)$ and $s(M L C):(1625 ; 1848)$ showed significantly higher results compared to all other presintered zirconia groups $(\mathrm{p}<0.001)$. The lowest mean and characteristic strength was observed with GC $(\sigma=817(803 ; 953)$, s(LS mean rank): 935, s(LS median rank): 935(868; 1007), s(ML): 932(875; 994) and s(MLC): (862; 1009)). The highest Weibull modulus estimated by LS for mean and median rank was observed with LZ (8.9 and 9.8(7.5; 12.9), respectively) and the lowest with ZE (5.1 and 5(3; 8.2), respectively). According to ML and MLC estimation, the control group showed the highest (10.1(6.6; 15.6), 9.2(5.8; 14.2), respectively), and CZ the lowest (5.6(3.8; 8.2), 5.0(3.2; 7.8), respectively) Weibull modulus. No differences in estimates of standard deviations of the normal distribution and the estimates of Weibull moduli for different estimation methods were found between all tested groups. CONCLUSIONS: Flexural strength of the tested hipped zirconia was higher than those of presintered ones according to both normal and Weibull distribution. LS (median rank) and ML estimates can be compared by a global test and by means of $95 \% \mathrm{CI}$. For corrected ML estimates the $95 \% \mathrm{CI}$ can be interpreted. Estimate calculations in Excel (LS, mean rank) provides information on $95 \%$ CI for the Weibull parameters.
\end{abstract}

DOI: https://doi.org/10.1016/j.jmbbm.2012.01.020

Posted at the Zurich Open Repository and Archive, University of Zurich

ZORA URL: https://doi.org/10.5167/uzh-62919

Journal Article

Accepted Version

Originally published at:

Stawarczyk, Bogna; Òzcan, Mutlu; Trottmann, Albert; Hämmerle, Christohp H F; Roos, Malgorzata (2012). Evaluation of flexural strength of hipped and presintered zirconia using different estimation methods of Weibull statistics. Journal of the Mechanical Behavior of Biomedical Materials, 10:227-234.

DOI: https://doi.org/10.1016/j.jmbbm.2012.01.020 


\section{Journal: J Mech Behav Biomed Mater}

Evaluation of flexural strength of hipped and presintered zirconia using different estimation methods of Weibull statistics

Bogna Stawarczyk ${ }^{1}$, Mutlu Özcan ${ }^{1}$, Albert Trottmann ${ }^{1}$, Christoph H. F. Hämmerle ${ }^{1}$, Malgorzata Roos ${ }^{2}$

${ }^{1}$ Clinic of Fixed and Removable Prosthodontics and Dental Material Science, Center of Dental Medicine, University of Zurich, Switzerland

${ }^{2}$ Division of Biostatistics, Institute of Social and Preventive Medicine, University of Zurich, Switzerland

Short title: Flexural strength and Weibull parameters of zirconia

Corresponding author details:

Dipl. Ing. Bogna Stawarczyk, MSc

Clinic of Fixed and Removable Prosthodontics and Dental Material Science

Center of Dental Medicine, University of Zurich, Switzerland

Plattenstrasse 11, 8032 Zurich, SWITZERLAND

Tel. $\quad+41446343365$

Fax $\quad+41446344305$

Email bogna.stawarczyk@zzm.uzh.ch 


\section{Abstract}

Objectives: This study determined the flexural strength of one hipped and eight presintered zirconia and evaluated the results using different estimation methods of Weibull statistics.

Materials and Methods: Presintered zirconia specimens were prepared in white state and sintered according to each manufacturer's instructions. One hipped zirconia acted as the control group. The specimens were loaded in a Universal Testing Machine (ISO 6872:2008). Data were analysed using "normal" (Levene-test, one-way ANOVA, Scheffé test) and "Weibull distribution" estimated by either Least Squares (LS) (mean (Excel) and median rank (MINITAB)), Maximum Likelihood (ML) (MINITAB) or ML (MINITAB) with a correction of BS EN 843-5:2006 (MLC) (alpha=0.05).

Results: According to normal $(\sigma)$ and Weibull distribution (s), three-point flexural strength (MPa) of the hipped zirconia ( $\sigma=1643(1507 ; 1782), \mathrm{s}($ LS mean rank): 1772, s(LS median rank): 1751 (1619;1894), s(ML): 1733 (1645;1826) and s(MLC): $(1625 ; 1848)$ showed significantly higher results compared to all other presintered zirconia groups $(p<0.001)$. The lowest mean and characteristic strength was observed with GC ( $\sigma=817(803 ; 953)$, $\mathrm{s}($ LS mean rank): 935, $\mathrm{s}(\mathrm{LS}$ median rank): 935(868;1007), s(ML): 932(875;994) and s(MLC): (862;1009)). The highest Weibull modulus estimated by LS for mean and median rank was observed with LZ (8.9 and 9.8(7.5;12.9), respectively) and the lowest with ZE (5.1 and 5(3;8.2), respectively). According to $\mathrm{ML}$ and $\mathrm{MLC}$ estimation, the control group showed the highest (10.1(6.6;15.6), 9.2(5.8;14.2), respectively), and CZ the lowest $(5.6(3.8 ; 8.2)$, 5.0(3.2;7.8), respectively) Weibull modulus. No differences in estimates of standard 
deviations of the normal distribution and the estimates of Weibull moduli for different estimation methods were found between all tested groups.

Conclusions: Flexural strength of the tested hipped zirconia was higher than those of presintered ones according to both normal and Weibull distribution. LS (median rank) and ML estimates can be compared by a global test and by means of $95 \% \mathrm{Cl}$. For corrected $\mathrm{ML}$ estimates the $95 \% \mathrm{Cl}$ can be interpreted. Estimate calculations in EXCEL (LS, mean rank) provides on information on $95 \% \mathrm{Cl}$ for the Weibull parameters.

Keywords: three point flexural strength, zirconia, Weibull modulus, estimation of Weibull statistics 


\section{Introduction}

In reconstructive dentistry, yttria stabilized zirconia (Y-TZP) is increasingly used for anterior and posterior fixed dental prosthesis (FDP). Zirconia has high flexural strength, fracture toughness and elasticity modulus (Evans, 1990; Filser et al., 2001; Sturzenegger et al., 2001; Lüthy et al., 2005; Fischer and Stawarczyk, 2007) and is highly biocompatible (Piconi and Maccauro, 1990). Clinical studies reported also high survival rate of zirconia frameworks but more failures of veneering ceramic (Vult von Steyern et al., 2005; Raigrodski et al., 2006; Sailer et al. 2007; Edelhoff et al. 2008; Schmitt et al., 2009).

CAD/CAM technology enables milling of zirconia blanks using two milling processes, namely soft-milling ("white state", presintered blanks) and hard-milling (hipped blanks). The blanks are pressed from zirconia powder under uniaxial, biaxial loading procedures or through ZIPping (ZIP: Zirconia Isostatic Pressed). They can be either presintered and in white state milled or fully sintered (HIP: Hot Isostatic Pressing) and then milled. Processing with presintered materials includes designing an enlarged reconstruction and milling of the frameworks from presintered zirconia blanks. The milled reconstruction has a linear shrinkage of $20-25 \%$ during sintering until it reaches the desired final dimension (Piwowarczyk et al., 2005). In contrast, hipped zirconia can be milled to the final dimensions because no further heat treatment, with associated dimensional change, is required (Filser et al., 2001; Besimo et al., 2001; Suttor et al., 2001).

The different production and milling procedures of the blanks can influence the mechanical properties of zirconia such as flexural strength and Weibull moduli (m) (Oh et al.,2010). The Weibull statistics is considered to characterize the structural reliability of brittle dental materials (Quinn and Quinn, 2010; Chong et al., 2002; Bona 
et al., 2003). Lower Weibull modulus indicates greater variability and thereby less reliability in the strength, due to flaws and defects in the material (Ritter and Readey, 1996). In the Weibull statistics, the characteristic strength (s) represents the 63.21 percentile of strength distribution (Weibull, 1951). Most dental ceramics are reported to have the Weibull modulus values in the range of 5-15 (Johnson, 1983).

Weibull parameters could be calculated with different estimation methods. Among these, linear regression analysis by means of least squares (LS) is commonly used that can be calculated either with a hand calculator, a simple spread-sheet, or common graphic software programs (Quinn and Quinn, 2010). A common alternative analysis to fit the data, is the Maximum Likelihood Estimation approach. It is a more advanced analysis that is more often preferred since the $90 \%$ or $95 \%$ confidence intervals $(\mathrm{Cl})$ on the estimates of the Weibull parameters are appreciably tighter than those of linear regression (Quinn and Quinn, 2010; Trustrum and Jayatilaka, 1979). The BS EN 843-5:2006 has proposed a correction method for Maximum Likelihood estimates.

For small sample size, there is a chance that different statistical methods lead to different estimates, as there is not much information about the underlying true distribution provided by the measurements (Quinn and Quinn, 2010). The objectives of this study therefore were to test the three-point flexural strength of nine different zirconia ceramics and estimate the Weibull parameters with different statistical methods. The primary hypothesis was to test whether the flexural strength results analysed with the normal distribution yields similar results compared to Weibull statistics. The secondary hypothesis was to test whether the choice of the estimation of Weibull statistic have an impact on the Weibull parameter. 


\section{Material and methods}

One hipped, (DC-Zirkon, control group) and eight presintered zirconia namely, ZENO ZR (ZE), GC ZR Disc CIP (GC), Ceramill ZI (CZ), Copran YZ (CY), InCoris ZI F0.5 (IC), Vita In-Ceram YZ (VI), Cercon ZR (CC) and LAVA Zirkon (LZ) were tested in this study (Table 1).

\subsection{Specimen preparation}

Three-point flexural strength of zirconia was measured according to ISO 6872: 2008. The specimens of the presintered zirconia were prepared in the white state. The zirconia blanks were cut with a low-speed diamond saw (Well 3241, Well Diamantdrahtsägen, Mannheim, Germany). The presintered and hipped specimens of all groups were ground to the final dimensions using SiC discs P220, P500, P1200, P2400 and P4000 (Silicon Carbide Paper, Struers, Ballerup, Denmark). As required by the standards, the two surfaces of the specimens did not differ more than $0.05 \mathrm{~mm}$ in parallelism. Thereafter, specimens in white state were sintered in the universal sintering oven (LHT 02/16, Nabertherm GmbH, Lilienthal/Bremen, Germany) according to each manufacturer's instructions (Table 2). Fifteen specimens were prepared for each group $(\mathrm{N}=135)$. After sintering procedures, specimens had the final dimensions of $1.2 \mathrm{~mm} \times 4 \mathrm{~mm} \times 25 \mathrm{~mm}$.

\subsection{Flexural strength measurement}

Before the flexural strength test, the dimensions of the specimens were measured with a digital micrometer (Mitutoyo, Andover, England) to the next $0.01 \mathrm{~mm}$. The specimens were tested dry at room temperature. They were placed in the appropriate sample holder and loaded in a Universal Testing Machine (Z010, Zwick, Ulm, Germany) at a cross-head speed of $1 \mathrm{~mm} / \mathrm{min}$ until failure. The flexural strength was calculated according to the following formula: $\sigma=3 \mathrm{NI} / 2 \mathrm{bd}^{2}$ ( $\sigma$ : flexural strength, $\mathrm{N}$ : 
fracture load $(\mathrm{N})$, l: distance between supports $(\mathrm{mm})$, b: width of the specimen $(\mathrm{mm})$, $\mathrm{d}$ : thickness of the specimen $(\mathrm{mm}))$.

\subsection{Statistical methods}

\subsubsection{Assumption of the underlying Weibull distribution}

The frequently used Weibull distribution has two parameters called scale or characteristic value (s), and shape or Weibull modulus (m) (Johnson et al., 1994). At least five different methods of the Weibull distribution have been described (Hallinan, 1993). Frequently, the Weibull statistics is estimated based on the statistical approach described by McCabe and Carrick (McCabe and Carried, 1986) and recently discussed by Quinn and Quinn (Quinn and Quinn, 2010). Denote the cumulative distribution function for the Weibull distribution by

$$
G(x)=1-\exp \left\{-\left(\frac{x-s_{0}}{s}\right)^{n}\right\}
$$

which corresponds for $\mathrm{s}_{0}=0$ to the following density

$$
g(x)=\frac{m}{s}\left(\frac{x}{s}\right)^{n-1} \exp \left\{-\left(\frac{x}{s}\right)^{m}\right\}
$$

\subsubsection{Least Squares Estimates (LS)}

In order to compute LS, in each sample group, $\hat{G}_{i}$, has to be the estimated for each observation (Bona et al., 2003; Hallinan, 1993; McCabe and Carrick, 1986; ISO C1239-07). In general, the "ith" position is a "typical“ population percentage near to which the "ith" ordered observation falls. Then, the logarithm of the flexural strength (X-axis) is plotted against $\log \log \left(1 /\left(1-\hat{G}_{i}\right)\right)$ on the $\mathrm{Y}$-axis and the linear regression fit of the scattered points is computed by means of LS. As suggested by McCabe and Carrick (McCabe and Carrick, 1986), the estimate of the modulus $\hat{m}$ of the assumed 
underlying Weibull distribution is the slope of the linear regression obtained by means of LS. In order to obtain a value of $\hat{G}_{i}$ McCabe and Carrick (McCabe and Carrick, 1986) suggested that the specimens within one test group should be ranked by calling the weakest specimen as "rank 1 " and the strongest as "rank n". The probability of failure $\hat{G}_{i}$ for each specimen from a group containing $n$ specimens is given by $\hat{G}_{i}=R(i) /(n+1)$, where $R(i)$ is the ranking number of the specimen.

Many alternative methods for estimating $\hat{G}_{i}$ in practical applications were suggested (Nelson, 1982). In MINITAB software, several options such as median rank (Benard), modified Kaplan-Meier (Rankit, Hazen's), Herd-Johnson (Van der Waerden, mean rank) and Kaplan-Meier are provided for $\hat{G}_{i}$ estimation. On the other hand, in SPSS Rankit, Tukey and Blom choices are used. Abernethy (Abernathy, 2009) recommended median ranks (Benard) as the most accurate and therefore considered as it the best approach to estimate $\mathrm{Y}$-axis plotting positions.

Different estimates for $\hat{G}_{i}$ lead to different plotting positions for (loglog(1/(1$\left.\hat{G}_{i}\right)$ ) on the Y-axis. For small sample size, the choice of the formula for $\hat{G}_{i}$ estimation can lead to different scatter plots and consequently to different LS estimates of both the modulus $(\hat{m})$ and characteristic strength $(\hat{s})$. In this study, we provide the LS estimates for the modulus and characteristic strength, estimated according to McCabe and Carrick (McCabe and Carrick, 1986). While LS median ranks were calculated using MINITAB, LS mean ranks were computed by manual calculation using EXCEL.

\subsubsection{Maximum Likelihood Estimates (ML)}


The general maximum likelihood $(\mathrm{ML})$ theory for estimation of the parameters of the Weibull distribution was provided by Nelson (Nelson, 1982) and in ISO C1239-07. The ML estimation brings several advantages. First, the $95 \% \mathrm{Cls}$ on the estimates of the Weibull parameters are obtained automatically and are tighter than those for linear regression (LS). Furthermore, in this method it is not necessary to use any formula for determination of the plotting positions $\hat{G}_{i}$. The iterative procedures facilitate the optimal parameter estimates of the underlying Weibull distribution that are considered as "most likely“ based on the observed data.

\subsubsection{Correction of the ML estimates}

Quinn and Quinn (Quinn and Quinn, 2010) mentioned that the ML estimate for the characteristic strength has negligible bias, but small correction factor is usually applied to correct or to achieve an „unbiased“ Weibull modulus estimate. In this study, such corrections were performed according to EN 843-5:2006. According to this norm, for $n=15$ specimens, the unbiasing factor for the $M L$ estimate of the Weibull modulus is equal to 0.908 . The corrections for the lower and upper bounds of the $95 \% \mathrm{Cl}$ for "Weibull modulus" were 1.173 and 0.716 and for the "characteristic strength" they were equal to -0.651 and 0.653 .

\subsubsection{Assumption of the underlying normal distribution}

When data are assumed to follow the "normal distribution", the standard techniques such as Levene-Test and one-way ANOVA can be applied. Estimates of the means (corresponding to the characteristic strength) and standard deviations (approximately corresponding to $1 /$ Weibull modulus) together with the corresponding $95 \% \mathrm{Cl}$ can be estimated under assumption of the normal distribution. The Levene-Test gives the information if there are differences in the variances between the groups. Materials in 
certain groups having smaller standard deviations are more reliable than others having larger standard deviations. If the assumption of the homogeneity of the variance is not violated, the one-way ANOVA can be computed to detect whether there are differences in mean flexural strength between the test groups.

\subsection{Statistical analysis}

Under assumption of the underlying normal distribution means of flexural strength, standard deviation (SD), minimum and maximum together with the corresponding 95\% confidence intervals $(95 \% \mathrm{Cl})$ were computed and presented graphically by boxplots. In addition, the Levene-test together with the Scheffe post-hoc test and the one-way ANOVA together with the Scheffe post-hoc test were applied in order to disclose the differences in SD and in mean flexural strength between the zirconia groups. The data were analysed using SPSS Version 15 (SPSS INC, Chicago, IL, USA)

Under assumption of the underlying Weibull distribution, the LS estimates of the modulus and characteristic flexural strength according to the plotting position (mean rank) (McCabe and Carrick, 1986) and (median rank, 95\%Cl) (Abernathy, 2009) were computed. In addition, the ML estimates of the modulus and the characteristic strength with the corresponding $95 \% \mathrm{Cl}$ and the "unibased" (corrected) version of the ML estimates were also computed. The Bartlett's modified likelihood ratio test (global test) was used to decide if there are differences in the modulus and in the characteristic flexural strength for ML and LS (median rank) estimates between the tested zirconia groups.

Probability plots were computed and the analysis was performed in MINITAB Version 14 (MINITAB, State College, PA, USA) and EXCEL (Office Microsoft Excel 2010). $P$ values smaller than 0.05 were considered statistically significant. 


\section{Results}

\subsection{Normal distribution}

Although the Levene test showed statistical significance $(p=0.032)$, no differences between variances of all tested groups could be indicated by the Scheffe post-hoc test. Consequently, it was impossible to decide which test groups show smaller SD (better reliability) than others. Therefore, we proceeded to the one-way ANOVA step and found differences $(p<0.001)$ in mean flexural strength between the test groups. Using the normal distribution, the control group showed the highest flexural strength compared to all other test groups (Fig.1, Table 3). Within the 8 test groups, CZ presented higher flexural strength results than those of GC and CC. The flexural strength results of $\mathrm{CY}$ and VI were significantly higher than that of GC. No statistical differences were found between the other groups.

\subsection{Weibull statistic}

\subsubsection{Least Squares Estimates (LS)}

\subsubsection{Mean rank (by EXCEL)}

Weibull statistics estimated by linear regression and calculated by EXCEL did not allow evaluation of their differences (no global test, no $95 \% \mathrm{Cl}$ ) between the groups. The highest characteristic strength was observed in the control group (1772 MPa) and the lowest in the GC (935 MPa) and CC (938 MPa) presintered zirconia groups. Presintered group ZE $(m=5.1)$ showed the lowest Weibull modulus and the group LZ the highest $(m=8.9)$ (Table 4, Fig. 2).

\subsubsection{2 median rank (by MINITAB)}

The global test for the characteristic strength revealed that there are differences $(p<0.001)$ in the estimates between the test groups. Control group $(1751(1619 ; 1894)$ 
$\mathrm{MPa}$ ) presented the highest characteristic strength. Within the presintered zirconia groups, CZ (1274(1174;1381) MPa) showed significantly higher characteristic values, being not statistically different from CY (1220(1099;1359) MPa). GC (935(868;1007) MPa) showed significantly lower values compared to ZE $(993(891 ; 1106)$ MPa), CZ (1274(1174;1381) MPa), CY (1220(1099;1354) MPa), IC (1025(952;1104)MPa) and VI (1166(1094;1242) MPa). All groups showed no statistical differences in the Weibull moduli $(p=0.216)$ (Table 4, Fig. 3).

\subsubsection{Maximum Likelihood estimates (ML) (by MINITAB)}

The global test for the characteristic strength revealed significantly differences $(p<0.001)$ in the estimates between the test groups. Control group $(1733(1645 ; 1826)$ $\mathrm{MPa}$ ) showed the highest characteristic flexural strength. Among the presintered materials, CZ showed $(1289(1171 ; 1419) \mathrm{MPa})$ the highest characteristic strength values, being not statistically different from CY $(1217(1111 ; 1333)$ MPa). GC (932(875;994) MPa) showed significantly lower values compared to ZE (992(902;1089) MPa), CZ (1289(1171;1419) MPa), CY $(1217(1111 ; 1333) \mathrm{MPa})$, IC $(1025(960 ; 1085) \mathrm{MPa})$ and VI (1174(1091;1262) MPa). All groups showed no statistical differences in the Weibull moduli $(p=0.292)$ (Table 4, Fig. 4).

\subsubsection{Correction of the Maximum Likelihood (MLC) (by MINITAB and EXCEL)}

There is no global test for the corrected ML estimates of the Weibull distribution. However, the $95 \% \mathrm{Cl}$ could be computed and interpreted as usual. Weibull parameters estimated by MLC showed that the control group $(1625 ; 1848)$ presented the highest characteristic strength and the lowest for CC $(844 ; 1029)$. All groups showed no statistical differences in the Weibull moduli, at $95 \% \mathrm{Cl}$ (Table 4). 


\section{Discussion}

Statistical differences were found in the mean flexural strength $(\mu)$ of "normal" and characteristic strength (s) using Weibull distribution assumption. Both normal and Weibull distribution methods showed that among all ceramics tested, hipped zirconia showed the highest flexural strength followed by $\mathrm{CZ}$. The lowest results were obtained with GC. Levene-test and Weibull moduli yielded similar findings. Between all test groups, no differences in SD (Levene-test) and Weibull moduli could be found. Therefore, the first hypothesis is accepted. However, the estimates obtained differed depending on the estimation methods. Therefore, the second hypothesis is rejected.

There was an association between the parameters of the Normal and Weibull distribution (Hallinan, 1993). The Weibull modulus governs typically the spread of the distribution and the characteristic strength influences mostly the probability. While the Weibull modulus corresponds to the inverse of standard deviation $(\sigma)$, the characteristic strength corresponds to the mean $(\mu)$ of the normal distribution. Weibull modulus represents a large degree of scatter in the distribution indicating that material is unpredictable, whereas higher " $m$ " represents a small degree of spread indicating the opposite. When differences are observed in the spread of the flexural strength between the groups, then one expects to obtain statistically different Weibull moduli. Based on the flexural strength results obtained in this study, no differences in the reliability of all tested zirconia groups could be found according to normal and Weibull distribution.

The hipped zirconia showed the highest flexural strength, which corresponds to a previous study (Fischer and Stawarczyk, 2007). Compared to presintered zirconia, the hipped material has a lower volume fraction of pores, higher strength, and an 
improved resistance to hydrothermal aging (Fischer and Stawarczyk, 2007; Oh et al., 2010). Since the latter requires more milling time and armamentarium, there is an increasing trend for the use of presintered ones. Among the presintered zirconia groups, $\mathrm{CC}, \mathrm{CY}$ and $\mathrm{VI}$ demonstrated the highest flexural strength. The lowest flexural strength was observed with the presintered GC. This material was sintered at the highest final sintering temperature of $1550^{\circ} \mathrm{C}$. All other tested presintered zirconia materials were sintered below $1550^{\circ} \mathrm{C}$. Hence, it can be stated that the sintering temperature had an impact on the flexural strength in term of mean and characteristic strength.

Statistical estimation methods are highly influenced by the number of specimens. According to Nelson (Nelson, 2009), with the sample size of $n=15$, the estimate $\hat{m}$ of the true Weibull modulus parameter $(\mathrm{m})$ would range between $\mathrm{m} / \mathrm{f}$ and $\mathrm{mf}$ with large probability of $95 \%$, where $f=1.72$. For instance, when the true modulus of Weibull distribution is equal to 7 in one particular test group, then the theoretical estimates $\hat{m}$ of the modulus based on 15 specimens would range between 4 and 12 with probability of 0.95 .

Opposite to MINITAB for LS (median rank) and ML estimates followed by a posthoc test (Bartlett's modified likelihood ratio tests together with the appropriate Bonferroni post-hoc), in EXCEL (LS, mean rank) estimates are hand computed. In EXCEL only the absolute estimates could be obtained but information on the $95 \% \mathrm{Cl}$ for the Weibull parameter is not available. MLC estimation method in this case provides the estimates without any global test between the groups. However, the $95 \% \mathrm{Cl}$ enable comparisons of the estimates between test groups. 
Only a few studies described how Weibull analysis for flexural strength measurements of ceramics was performed (Bona et al., 2003). In the majority of the studies, it was stated that the variability of the flexural strength values was determined by Weibull-analysis or Weibull analysis was performed for all of the groups (Hjerppe et al., 2009; Ashkanani et al.,2008) without mentioning whether LS/ML was used or not. When LS is used, definition of the plotting positions has to be explicitly described (mean or median rank). Also when ML is used, the statement whether the raw or corrected estimates are reported, should be given. Only when this information is available, study results could be compared with one another. Future studies therefore should provide at least $95 \% \mathrm{Cl}$ if not global test results for the estimates, as the absolute values cannot be analysed without any information on $95 \% \mathrm{Cl}$ reliably. At this stage, the results of this study cannot be compared with those of others due to the lack of information on the estimation methods and $95 \% \mathrm{Cl}$ (Hjerppe et al., 2009; Ashkanani et al.,2008). Nevertheless, estimation methods should be taken into consideration when interpreting data limited number of specimens.

\section{Conclusions}

Within the limitations of this in-vitro study, it can be concluded that:

1. Mean and characteristic flexural strength showed significant differences between the tested groups. Hipped zirconia showed the highest flexural strength followed by presintered CZ, and GC being the lowest.

2. Levene-test and Weibull moduli yielded to similar findings for the flexural strength of the zirconia ceramics tested. Also, no differences were found in SD (Levene-test) and Weibull moduli. 
3. Estimate calculations in EXCEL (LS, mean rank) provides no information on 95\% Cl for the Weibull parameters.

4. Statistical differences between the test groups could be computed for LS and ML estimates using MINITAB.

\section{Acknowledgments}

The authors would like to thank the companies for providing the materials. They would also like to thank Dr. Andreas Ender for his support by sintering procedures of the zirconia specimens.

\section{Conflict of interest}

The authors declare no conflicts of interest. 


\section{Tables}

Table 1. The abbraviations, brands, manufacturers and Batch-No of the tested materials.

Table 2. Sintering parameters of all tested zirconia groups.

Table 3. Flexural strength, $95 \%$ confidence interval, standard deviation, minimum and maximum (normal distribution).

Table 4. Different estimated Weibull parameters of all tested groups.

\section{Figures}

Fig. 1 - Boxplot of 3-point flexural strength of all tested zirconia groups

Fig. 2 - Probability Plot for Weibull parameter estimated by Least Squares (mean rank, by EXCEL).

Fig. 3 - Probability Plot for Weibull parameter estimated by Least Squares (median rank, by MINTAB).

Fig 4 - Probability Plot for Weibull parameter estimated by Maximum Likelihood by MINTAB. 


\section{References}

Abernathy, R.B., 2009. The new Weibull Handbook, $5^{\text {th }}$ Edition.

Ashkanani, H.M., Raigrodski, A.J., Brian, D., Heindl, H., Mancl, L.A., 2008. Flexural and shear bond strength of $\mathrm{ZrO} 2$ and a high-noble alloy bonded to their corresponding porcelains. J. Prosthet. Dent. 100, 274-284.

Besimo, C.E., Spielmann, H.P., Rohner, H.P., 2001. Computed-assisted generation of all-ceramic crowns and fixed partial dentures. Int. J. Comput. Dent. 4, 243-262.

Bona, A.D., Anusavice, K.J., DeHoff, P.H., 2003. Weibull analysis and flexural strength of hot-pressed core and veneered ceramic structures. Dent. Mater. 19, 662669.

BS EN 843-5, 2006. Advanced technical ceramics-Mechanical properties of monolithic ceramics at room temperature. Part 5: Statistical analysis. London, UK: British Standard Institute.

Chong, K.H., Chai, J., Takahashi, Y., Wozniak, W., 2002. Flexural strength of InCeram alumina and In-Ceram zirconia core materials. Int. J. Prosthodont. 15, 183188.

Edelhoff, D., Beuer, F., Florian, W., Johnen, C., 2008. HIP zirconia fixed partial dentures-clinical results after 3 years of clinical service. Quintessence Int. 39, 459471.

Evans, A.G., 1990. Perspective on the development of high-toughness ceramics. J Am Ceram Soc 73, 187-206.

Filser, F., Kocher, P., Weibel, F., Lüthy, H., Schärer, P., Gauckler, L.J., 2001. Reliability and strength of all-ceramic dental restorations fabricated by direct ceramic machining (DCM). Int. J. Comp. Dent. 4, 89-106. 
Fischer, J., Stawarczyk, B., 2007. Compatibility of machined Ce-TZP/AI2O3 nanocomposite and a veneering ceramic. Dent. Mater. 23, 1500-1505.

Hallinan, A.J., 1993. A Review of the Weibull Distribution. Journal of Quality Technology 25, 85-93.

Hjerppe, J., Vallittu, P.K., Fröberg, K., Lassila, L.V.J., 2009. Effect of sintering time on biaxial strength of zirconium dioxide. Dent. Mater. 25, 166-171.

ISO 6872, 2008. Dentistry-ceramic materials. Geneva, Switzerland: International Organization for Standardization.

ISO C1239-07, 2007. Standard practice for reporting uniaxial strength data and estimating Weibull distribution parameters for advanced ceramics.

Johnson, C.A., 1982. Fracture static of multiple flaw distribution. In: Richard, C., Hasselmann, D.P., Lange, F.F., editors. Fracture Mechanics of Ceramics, Vol 5. New York: Plenum Press; p. 365-389.

Johnson, N.L., Kotz, S., Balakrishnan, N., 1994. Continuous Univariate Distributions. Volume 1. Second Edition. John Wiley \& Sons, Inc.

Lüthy, H., Filser, F., Loeffel, O., Schumacher, M., Gauckler, L.J., Hämmerle, C.H.F., 2005. Strength and reliability of four unit all-ceramic posterior bridges. Dent. Mater. 21, 930-937.

McCabe, J.F., Carrick, T.E., 1986. A statistical approach to the mechanical testing of dental materials. Dent. Mater. 2, 139-142.

Nelson, W., 1982. Applied life data analysis. John Wiley \& Sons, Inc. p. 231-357.

Oh, G.J., Yun, K.D., Lee, K.M., Lim, H.P., Park, S.W., 2010. Sintering behavior and mechanical properties of zirconia compacts fabricated by uniaxial press forming. J. Adv. Prosthodont. 2, 81-87.

Piconi, C., Maccauro, G., 1999. Zirconia as a ceramic biomaterial. Biomaterials. 20,125. 
Piwowarczyk, A., Ottl, P., Lauer, H.C., Kuretzky, T., 2005. A clinical report and overview of scientific studies and clinical procedures conducted on the 3M ESPE Lava all-ceramic system. J. Prostodont. 14, 39-45.

Quinn JB, Quinn GD., 2010. A practical and systematic review of Weibull statistics for reporting strengths of dental materials. Dent. Mater. 26,135-147.

Raigrodski, A.J., Chiche, G.J., Potiket, N., Hochstedler, J.L., Mohamed, S.E., Billiot, S., Mercante, D.E., 2006. The efficacy of posterior three-unit zirconium-oxide-based ceramic fixed partial dental prostheses: a prospective clinical pilot study. J. Prosthet. Dent. 96, 237-244.

Ritter, L., Readey, M.J., 1996. Effect of heat treatment on grain size, phase assemblage, and mechanical properties of 3 mol\% Y-TZP. J. Am. Ceram. Soc. 79, 2331-2340.

Sailer, I., Fehér, A., Filser, F., Gauckler, L.J., Lüthy, H., Hämmerle, C.H.F., 2007. Five-Year clinical results of zirconia frameworks for posterior fixed partial dentures. Int. J. Prosthodont. 20, 383-388.

Schmitt, J., Holst, S., Wichmann, M., Reich, S., Gollner, M., Hamel, J., 2009. Zirconia posterior fixed partial dentures: a prospective clinical 3-year follow-up. Int. J. Prosthodont. 22, 597-603.

Sturzenegger, B., Fehér, A., Lüthy, H., Schärer, P., Gauckler, L.J., 2001, Reliability and strength of all-ceramic dental restorations fabricated by direct ceramic machining (DCM). Int. J. Comp. Dent. 4, 89-106.

Suttor, D., Bunke, K., Hoescheler, S., Hauptmann, H., Hertlein, G., 2001. LAVA-The system for all-ceramic ZrO2 crown and bridge frameworks. Int. J. Comput. Dent. 4, 195-206.

Trustrum, K., Jayatilaka Ade, S., 1979. On estimating the Weibull modulus for a brittle material. J. Mater. Sci. 14, 1080-1084. 
Vult von Steyern, P.V., Carlson, P., Nilner, K., 2005. All-ceramic fixed partial dentures designed according to the DC-Zircon technique. A 2-year clinical study. J. Oral. Rehabil. 32, 180-7.

Weibull, A., 1951. A statistical distribution function of wide applicability. J. Appl. Mech. 18, 293-297. 
Table 1. The abbreviations, brands, manufacturers and Batch-No of the tested materials.

\begin{tabular}{|l|l|l|l|}
\hline Abbreviations & Zirconia brands & Manufacturers & Batch-No. \\
\hline Control group & DC-Zikon & DCS, Allschwill, Switzerland & S304516B \\
\hline ZE & ZENO ZR & Wieland, Pforzheim, Germany & $20081010-21$ \\
\hline GC & GC ZR Disc CIP & GC Europe, Leuven, Belgium & 2025 \\
\hline CZ & Ceramill ZI & Amann Girrbach, Koblach, Austria & $0904638 / 2$ \\
\hline CY & Copran YZ & White Peak, Essen, Germany & 560018 \\
\hline IC & InCoris ZI F0.5 & Sirona Dental, Bensheim, Germany & 1005300 \\
\hline VI & Vita In-Ceram YZ & Vita Zahnfabrik, Bad Säckingen, Germany & 26850 \\
\hline CC & Cercon ZR & DeguDent, Hanau, Germany & 20024985 \\
\hline LZ & LAVA Zirkon & 3M ESPE, Seefeld, Germany & 308042 \\
\hline
\end{tabular}


Table 2. Sintering parameters of all tested zirconia groups.

\begin{tabular}{|c|c|c|c|c|c|c|}
\hline Groups & $\begin{array}{l}\text { Heat } \\
\text { rate } \\
\left({ }^{\circ} \mathrm{C} / \mathrm{min}\right) \\
\end{array}$ & $\begin{array}{l}\text { Holding } \\
\text { temperature and } \\
\text { time }\left({ }^{\circ} \mathrm{C}, \mathrm{min}\right)\end{array}$ & $\begin{array}{l}\text { Final } \\
\text { temperature } \\
\left({ }^{\circ} \mathrm{C}\right)\end{array}$ & $\begin{array}{l}\text { Holding } \\
\text { time (min) }\end{array}$ & $\begin{array}{l}\text { Cooling rate } \\
\left({ }^{\circ} \mathrm{C} / \mathrm{min}\right)\end{array}$ & $\begin{array}{l}\text { Door opening by } \\
\left({ }^{\circ} \mathrm{C}\right)\end{array}$ \\
\hline $\begin{array}{l}\text { Control } \\
\text { group }\end{array}$ & - & & - & - & - & - \\
\hline ZE & 10 & $\begin{array}{l}900,30 \text { further } \\
\text { with } 3^{\circ} \mathrm{C} / \mathrm{min}\end{array}$ & 1450 & 120 & 10 & Roomtemperature \\
\hline GC & 12 & - & 1550 & 180 & 12 & Roomtemperature \\
\hline $\mathrm{CZ}$ & 8 & - & 1450 & 120 & free & $200^{\circ} \mathrm{C}$ \\
\hline CY & 6 & - & 1450 & 120 & free & $160^{\circ} \mathrm{C}$ \\
\hline IC & 17 & - & 1530 & 120 & free & $400^{\circ} \mathrm{C}$ \\
\hline VI & 17 & - & 1530 & 120 & free & $400^{\circ} \mathrm{C}$ \\
\hline $\mathrm{CC}$ & * & * & 1350 & 120 & * & * \\
\hline $\mathrm{LZ}$ & 10 & - & 1500 & 120 & free & $250^{\circ} \mathrm{C}$ \\
\hline
\end{tabular}


Table 3: Flexural strength, $95 \%$ confidence interval, standard deviation, minimum and maximum (normal distribution).

\begin{tabular}{|c|c|c|c|c|c|}
\hline Groups & Mean (MPa) & $95 \% \mathrm{Cl}$ & SD (MPa) & Minimum (MPa) & Maximum (MPa) \\
\hline Control group & $1643^{a}$ & $1507 ; 1782$ & $63.8^{z}$ & 928 & 1937 \\
\hline ZE & $913^{\mathrm{DCd}}$ & $801 ; 1026$ & $52.2^{z}$ & 567 & 1176 \\
\hline GC & $817^{d}$ & $803 ; 953$ & $45.2^{z}$ & 630 & 1066 \\
\hline $\mathrm{CZ}$ & $1195^{b}$ & $1070 ; 1321$ & $58.3^{z}$ & 928 & 1697 \\
\hline $\mathrm{CY}$ & $1124^{\mathrm{DC}}$ & $992 ; 1257$ & $61.6^{z}$ & 696 & 1443 \\
\hline IC & $963^{\mathrm{bcd}}$ & $883 ; 1044$ & $37.2^{z}$ & 656 & 1166 \\
\hline $\mathrm{VI}$ & $1106^{\mathrm{bc}}$ & $1019 ; 1193$ & $40.3^{z}$ & 871 & 1405 \\
\hline $\mathrm{CC}$ & $868^{\mathrm{cd}}$ & $774 ; 961$ & $43.3^{z}$ & 527 & 1127 \\
\hline $\mathrm{LZ}$ & $939^{\text {bcd }}$ & $870 ; 1008$ & $31.8^{z}$ & 794 & 1214 \\
\hline
\end{tabular}


Table 4: Different estimated Weibull parameters of all tested groups.

\begin{tabular}{|c|c|c|c|c|}
\hline $\begin{array}{l}\text { Zirconia } \\
\text { groups }\end{array}$ & $\begin{array}{l}\text { estimated by } \\
\text { Least Squares } \\
\text { mean rank } \\
(95 \% \text { CI) by } \\
\text { EXCEL }\end{array}$ & $\begin{array}{l}\text { estimated by Least } \\
\text { Squares median } \\
\text { rank }(95 \% \mathrm{Cl})\end{array}$ & $\begin{array}{l}\text { estimated by } \\
\text { Maximum } \\
\text { Likelihood }(95 \% \\
\text { Cl) }\end{array}$ & $\begin{array}{l}\text { estimated by } \\
\text { corrected Maximum } \\
\text { Likelihood (95\% CI) }\end{array}$ \\
\hline \multicolumn{5}{|c|}{ Weibull moduli } \\
\hline Control group & 6.4 & $7.1(3.1,15.9)^{\mathrm{a}}$ & $10.1(6.6,15.6)^{\mathrm{a}}$ & $(5.8,14.2)$ \\
\hline ZE & 5.1 & $5.0(3.0,8.2)^{a}$ & $5.7(3.7,8.7)^{a}$ & $5.2(3.2,8.0)$ \\
\hline GC & 7.5 & $7.2(4.3,12.0)^{\mathrm{a}}$ & $8.3(5.5,12.6)^{a}$ & $7.6(4.8,11.7)$ \\
\hline $\mathrm{CZ}$ & 6.2 & $6.8(5.0,9.1)^{a}$ & $5.6(3.8,8.2)^{a}$ & $5.0(3.2,7.8)$ \\
\hline $\mathrm{CY}$ & 5.3 & $5.1(3.1,8.4)^{a}$ & $5.9(3.8,8.9)^{a}$ & $5.3(3.3,8.2)$ \\
\hline IC & 7.5 & $7.3(4.1,12.6)^{\mathrm{a}}$ & $8.8(5.8,13.3)^{a}$ & $8.0(5.0,12.3)$ \\
\hline $\mathrm{VI}$ & 8.5 & $8.7(6.4,11.7)^{a}$ & $7.4(5.1,10.8)^{a}$ & $6.8(4.2,10.4)$ \\
\hline $\mathrm{CC}$ & 5.7 & $5.5(3.2,9.5)^{a}$ & $6.6(4.3,10.0)^{\mathrm{a}}$ & $6.0(3.8,9.3)$ \\
\hline LZ & 8.9 & $9.8(7.5,12.9)^{\mathrm{a}}$ & $7.7(5.3,11.2)^{\mathrm{a}}$ & $7.0(4.4,10.8)$ \\
\hline p-values & & $p=0.207$ & $p=0.357$ & \\
\hline \multicolumn{5}{|c|}{ Characteristical flexural strength (MPa) } \\
\hline Control group & 1772 & $1751(1619,1894)^{\mathrm{a}}$ & $\begin{array}{l}1733 \\
(1645,1826)^{a}\end{array}$ & $(1625,1848)$ \\
\hline ZE & 994 & $993(891,1106)^{c}$ & $992(902,1089)^{\mathrm{C}}$ & $(883,1112)$ \\
\hline GC & 935 & $935(868,1007)^{d}$ & $932(875,994)^{d}$ & $(862,1009)$ \\
\hline $\mathrm{CZ}$ & 1289 & $1274(1174,1381)^{b}$ & $\begin{array}{l}1289 \\
(1171,1419)^{b}\end{array}$ & $(1147,1448)$ \\
\hline CY & 1222 & $1220(1099,1354)^{\mathrm{bC}}$ & $\begin{array}{l}1217 \\
(1111,1333)^{b c}\end{array}$ & $(1089,1361)$ \\
\hline IC & 1032 & $1025(952,1104)^{c}$ & $\begin{array}{l}1021 \\
(960,1085)^{c}\end{array}$ & $(947,1100)$ \\
\hline $\mathrm{VI}$ & 1171 & $1166(1094,1242)^{C}$ & $\begin{array}{l}1174 \\
(1091,1262)^{c}\end{array}$ & $(1075,1282)$ \\
\hline $\mathrm{CC}$ & 938 & $937(851,1032)^{c d}$ & $\begin{array}{l}932 \\
(860,1011)^{c d}\end{array}$ & $(844,1029)$ \\
\hline LZ & 992 & $984(929,1041)^{c}$ & $994(926,1066)^{c}$ & $(913,1081)$ \\
\hline p-values & & $p<0.001$ & $p<0.001$ & - \\
\hline
\end{tabular}


Fig. 1 - Boxplot of 3-point flexural strength of all tested zirconia groups

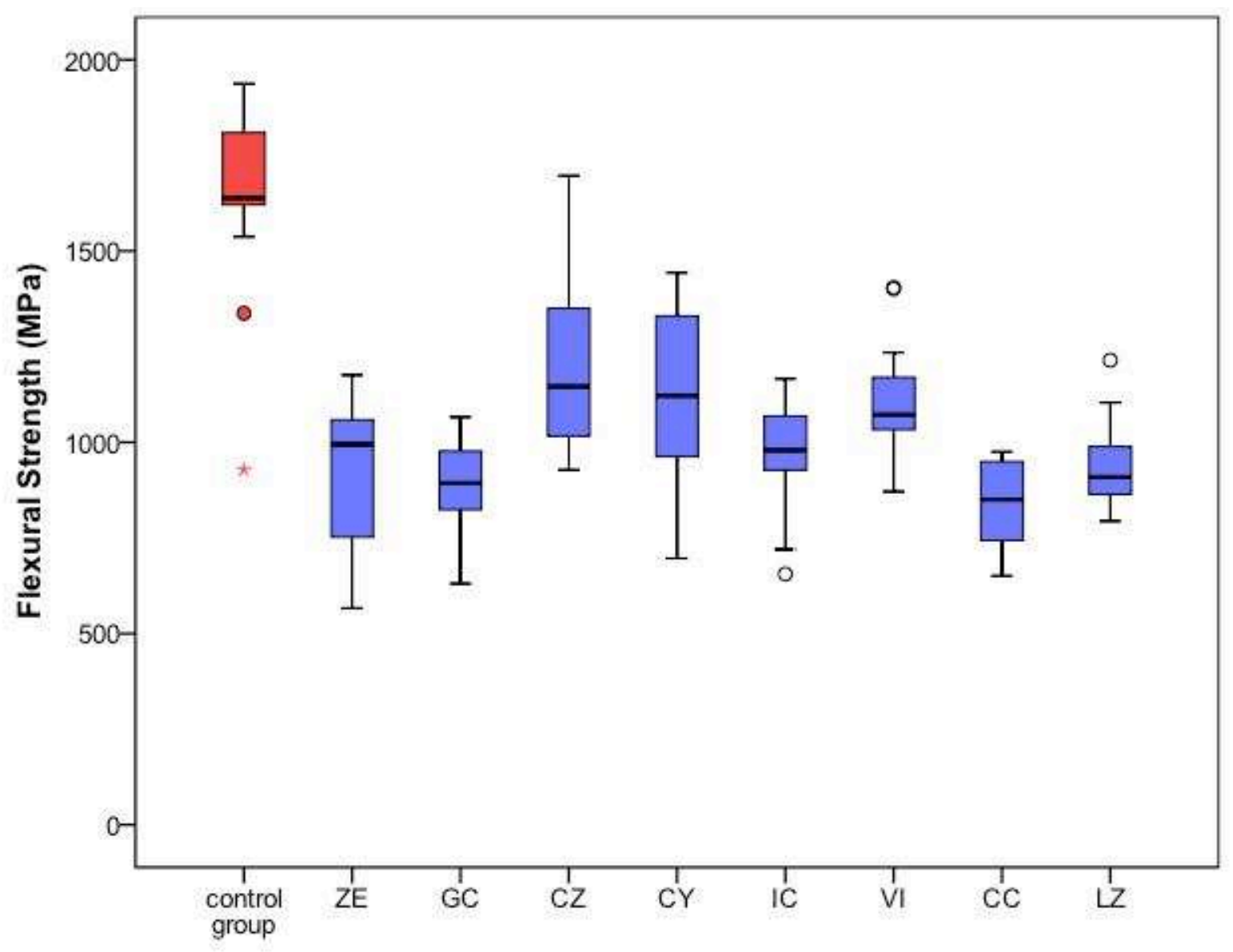


Fig. 2 - Probability Plot for Weibull parameter estimated by Least Squares (mean rank by EXCEL).

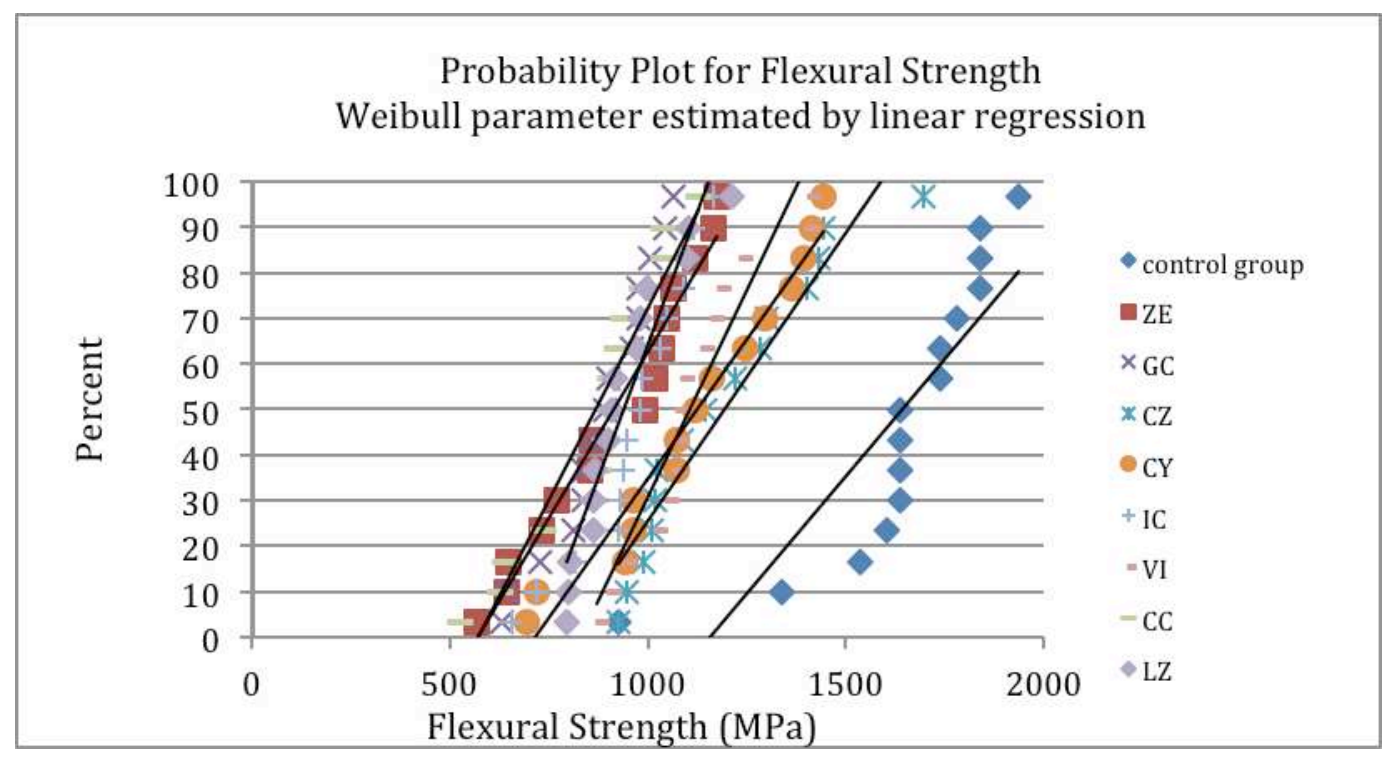


Fig. 3 - Probability Plot for Weibull parameter estimated by Least Squares (median rank) by MINITAB.

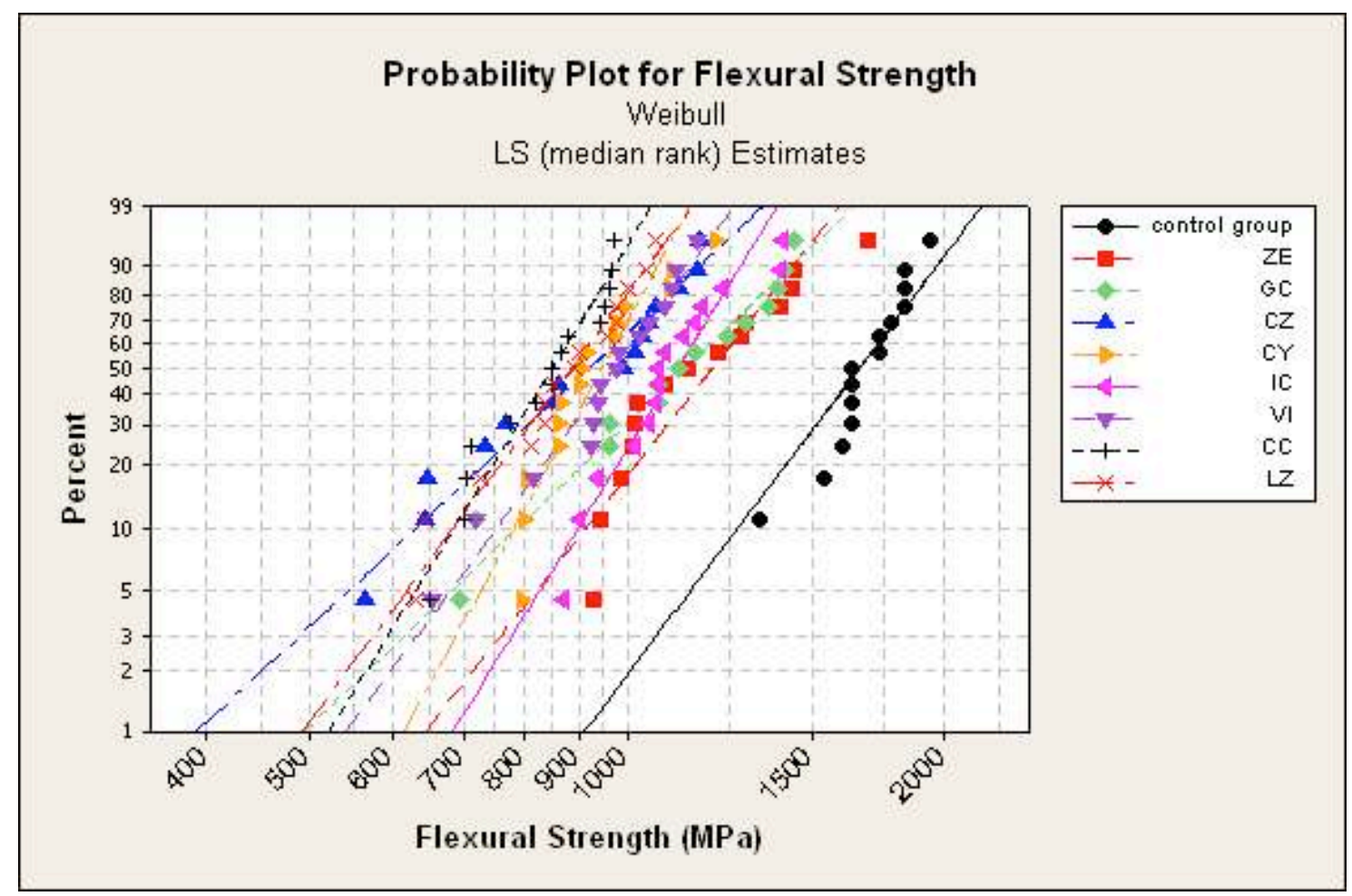


Fig. 4 -Probability Plot for Weibull parameter estimated by Maximum Likelihood by MINITAB.

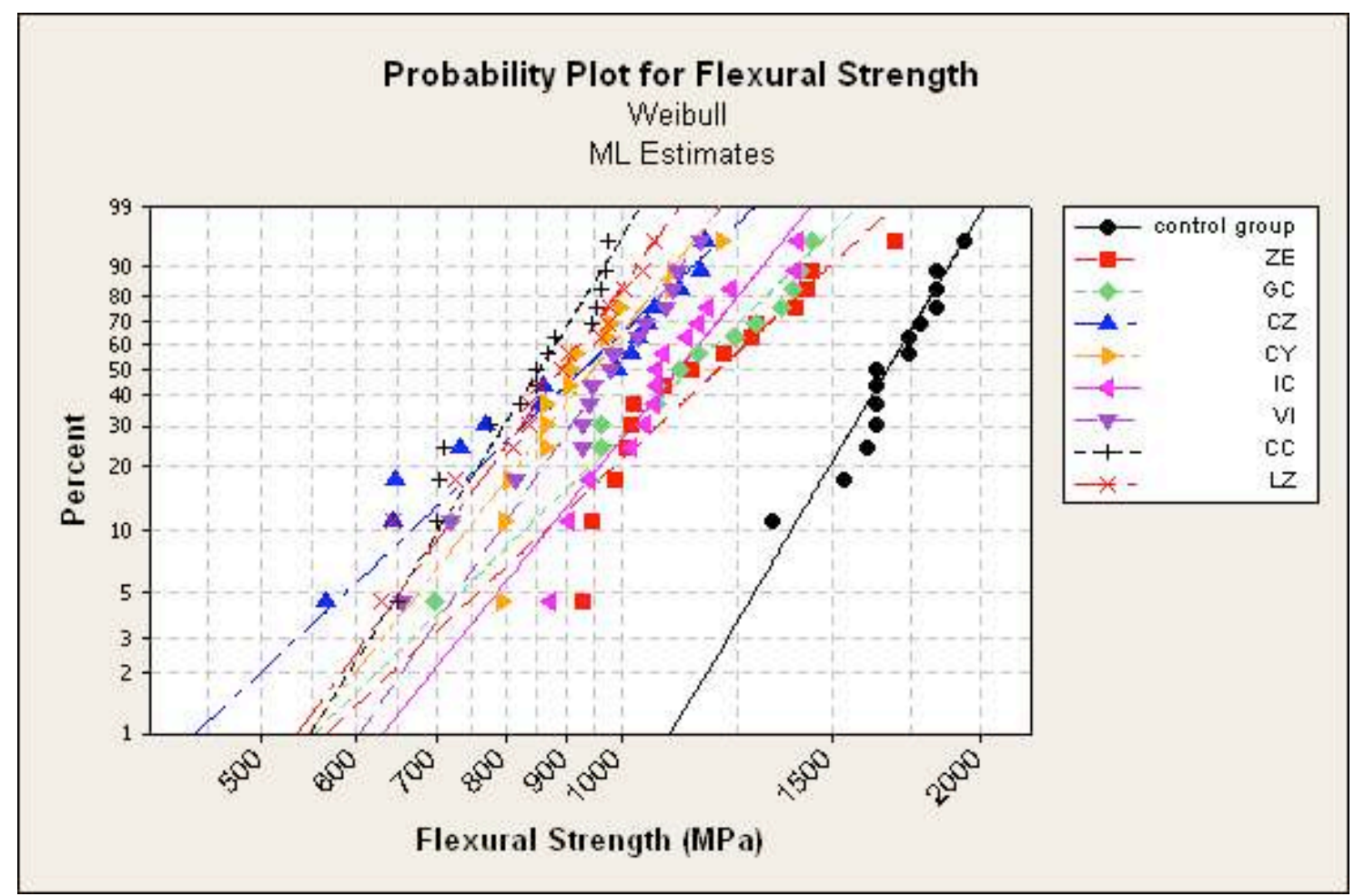

